The International Journal of Engineering and Science (IJES)

|| Volume || 6 || Issue || 4 || Pages || PP 15-23 || 2017 ||

ISSN (e): $2319-1813$ ISSN (p): $2319-1805$

THE IJES

\title{
Application of Variable Inductors in a DC/DC Converter to Increase the Operating Range of the Power Tracker at Low Solar Levels
}

\author{
Hassan Nasiri Mardanghom, Esmaeil Najafi Aghdam, \\ Mohammad Ali Baherifard \\ Department of Electronics Engineering, Sahand University of Technology, Tabriz, Iran
}

\begin{abstract}
Maximum power transfer in solar micro-grid applications is achieved by impedance matching with a dc-dc converter with maximum power point tracking by the incremental conductance method. Cuk $d c$ to $d c$ converters because of the increase and decrease voltage capability is an important and two inductors in the input and output decrease current ripple significantly. This paper describes how to use non-linear inductors in Cuk converter and designs values of capacitors properly. Because of the Cuk converter uses two inductors, use of variable inductors has great value and reduce the size and cost of inductors and increases the operating range of the tracker to recover solar energy at low solar levels. In other words, the range of operation is extended for low light levels or partially shaded solar panels. The MPPT controller with a variable inductance is robust and reliable over the full operating range. The validity of the proposed converter is verified with computer simulations using PSCAD/EMTDC.
\end{abstract}

Keywords: Variable Inductor, Photovoltaic (PV), Impedance Matching, Maximum Power Point Tracking (MPPT).

Date of Submission: 04 April 2017

Date of Accepted: 22 April 2017

\section{INTRODUCTION}

There have been renewed interests in solar microgrids in recent years, and thus, led to further studies in maximum power point tracking (MPPT). A method of modeling and simulation of photovoltaic arrays studied in [1]. Evaluation of current controllers for distributed power generation systems and review of the single phase photovoltaic module integrated converter topologies with three different DC link configurations discussed in [23]. A single-stage grid connected inverter topology for solar PV systems with maximum power point tracking and modeling, analysis and testing of autonomous operation of an inverter-based microgrid studied in [4-5]. Application of the short-current pulse-based MPPT method is important. So, short-current pulse-based adaptive MPPT method for PV power generation systems discussed in [6]. Stability of photovoltaic and wind turbine grid-connected inverters for a large set of grid impedance values and an integrated inverter with maximum power tracking for grid-connected PV systems and topologies of single-phase inverters for small distributed power generators studied in [7-9]. The photovoltaic (PV) module-integrated converter, which connects PV panels to single-phase ac grid in a modular structure, has become an important trend in PV market [10-13]. MPPT in solar photovoltaic (PV) microgrid systems is normally achieved either by the perturb and observe method or by the incremental conductance method (ICM). In the ICM approach, the output resistance of the PV panel is equal to the load resistance as expected from the celebrated maximum power transfer theorem. This may be by linearizing the $I-V$ output characteristic of a PV panel about the operating point, as illustrated in Fig. 1.

Thus, the equivalent resistance $r$ at the maximum power point is given by:

$-r=-\frac{\Delta V}{\Delta I}=R_{L R}=\frac{V_{P}}{I_{P}}$

Where $R_{L R}$ is the regulated resistance in order to achieve MPPT, $V_{P}$ and $I_{P}$ are the PV voltage and current at the MPP. The actual load resistance is matched to $r$ by a Cuk converter through the control of the duty cycle $D$, the regulated resistance $R_{L R}$ is as follows [14]: 
$R_{L R}=\frac{V_{P}}{I_{P}}=\frac{\frac{(1-D)}{D} V_{O}}{\frac{D}{(1-D)} I_{O}}=\frac{(1-D)^{2}}{D^{2}} R_{L}$

Where $D$ is the duty cycle of the Cuk converter and $R_{L}$ represents the microgrid load connected to the PV panel. Consider two levels of illumination intensity at points 1 and 2 in Fig. 1(c), the current at the MPP decreases going from point 1 to point 2 that changes the value of the PV resistance at the MPP. In order to achieve MPPT, the regulated resistance $R_{L R}$ should be adjusted by changing the duty cycle $D$ in (2).

In this paper, the solar module output characteristics and model of solar panel are represented. The role of the variable inductor in the stable operation of the Cuk converter in conduction current mode is explained and used Inductor structure and desigined capacitor value in converter is presented.

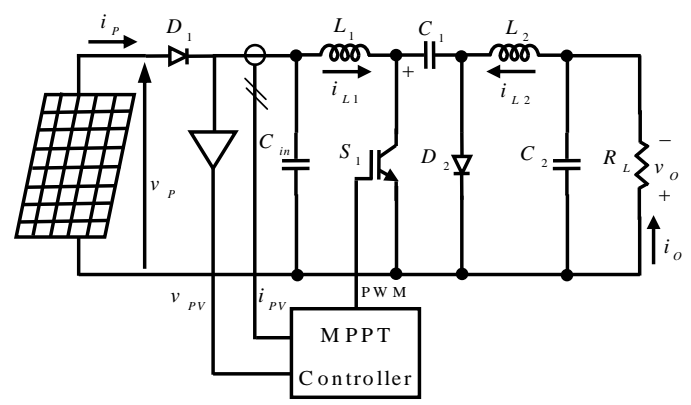

(a)

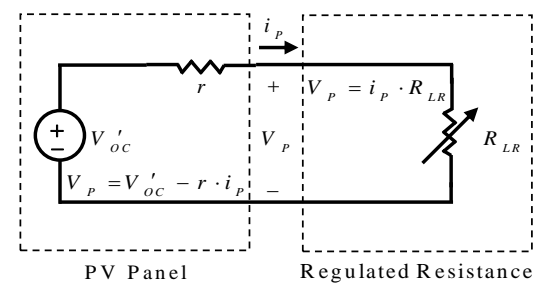

(b)

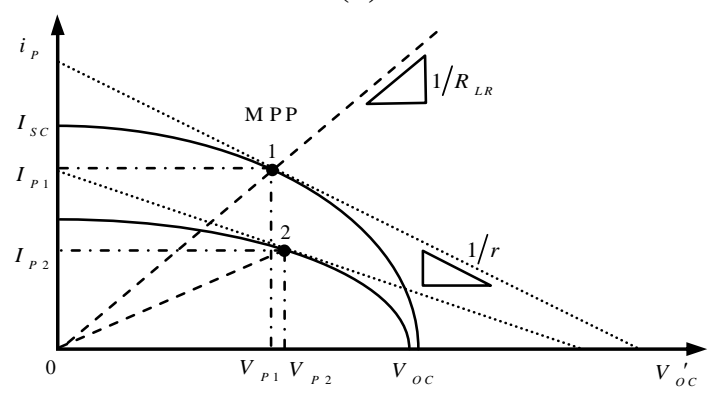

(c)

Fig. 1. (a) Maximum power transfer in a PV microgrid, (b) Thevenin equivalent circuit, (c) MPPT based on impedance matching.

\section{MODEL AND CHARACTERISTICS OF SOLAR PANEL}

The solar module output characteristics are represented by an equivalent circuit model in Fig. 2 with the following equations, the parameter values given are for the Sanyo HIP 210W module [15].

The output current is given by:

$I=I_{p h}-I_{s a t}\left[e^{q V /\left(n K T_{c e l} N_{s}\right)}-1\right]$

Where $q$ charge on an electron $\left(q=1.6022 \times 10^{-19} C\right), \quad K \quad$ Boltzmann constant $\left(K=1.38 \times 10^{-23} \mathrm{~m}^{2} \cdot \mathrm{kg} \cdot \mathrm{s}^{-2} K\right), n$ ideality factor $(n=1.5), I$ output current [calculated in (3)], $I_{p h}$ photogenerated current [calculated in (4)], $I_{s a t}$ saturation current [calculated in (5)], $V$ output voltage, $N$ s number of cells in series $(82), R_{S}$ series resistance $(0.004 \Omega)$ and $T_{\text {cell }}$ solar panel temperature $(K)$. 
The photo generated current $I_{p h}$ is given by:

$$
I_{P h}=I_{\text {scref }} \frac{G}{G_{r e f}}\left[1+\alpha_{\text {isc }}\left(T_{\text {cell }}-T_{r e f}\right)\right]
$$

Where $I_{\text {scref }}$ short circuit current at standard conditions $(5.57 \mathrm{~A}), G$ solar irradiance; $G_{\text {ref }}$ reference solar irradiance at standard conditions $\left(1000 \mathrm{~W} / \mathrm{m}^{2}\right), \alpha_{i s c}$ short circuit current temperature coefficient (1.67 $m \mathrm{~A} /{ }^{\circ} \mathrm{C}$ ) and $T_{r e f}$ reference temperature at standard conditions (298 K ).

The saturation current $I_{\text {sat }}$ is given by:

$$
I_{s a t}=\frac{I_{P h}}{e^{q V /\left(n K T_{c e l} N_{s}\right)}-1}
$$

The open circuit voltage $V_{o c}$ is given as follows:

$V_{o C}=V_{o c r e f}+\alpha_{V O C}\left(T_{\text {cell }}-T_{\text {ref }}\right)$

Where $V_{o c \text { ref }}$ open circuit voltage at standard operating conditions $(50.9 \mathrm{~V}), \alpha_{V o c}$ open circuit voltage temperature coefficient $\left(-0.127 \mathrm{~V} /{ }^{\circ} \mathrm{C}\right)$.

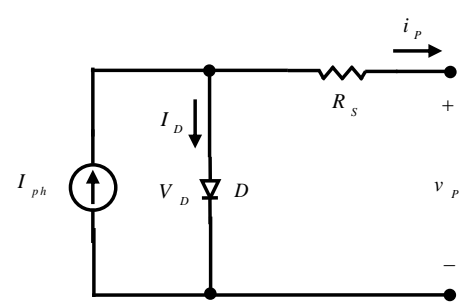

Fig. 2. Equivalent circuit of a PV module.

\section{MINIMUM AND VARIABLE INDUCTANCE IN CUK CONVERTER}

The minimum inductances in a Cuk converter in CCM are:

$$
\begin{aligned}
& L_{1, \text { min }}=\frac{(1-D)^{2}}{2 D f_{s}} R_{L} \\
& L_{2, \text { min }}=\frac{(1-D)}{2 f_{s}} R_{L}
\end{aligned}
$$

Where $f_{s}$ is the switching frequency.

The average input current in the Cuk converter $I_{P}$ and output current $I_{O}$ is as follows:

$I_{P}=\frac{D}{1-D} I_{o}$

The output current $I_{o}$ is the average current in the inductor of the cuk converter.

The equation of first minimum inductance can be rewritten:

$$
\begin{aligned}
& L_{1, \text { min }}=\frac{(1-D)^{2}}{2 D f_{S}} R_{L} \\
& =\frac{(1-D)^{2}}{2 D f_{s}} \frac{V_{o}}{I_{o}} \\
& =\frac{(1-D)^{2}}{2 D f_{S}} \frac{\frac{D V_{P}}{1-D}}{I_{O}} \\
& =\frac{(1-D) V_{P}}{2 f_{S} I_{O}}
\end{aligned}
$$

And for second minimum inductance:

$L_{2, \text { min }}=\frac{(1-D) R_{L}}{2 f_{S}}$ 


$$
\begin{aligned}
& =\frac{(1-D) V_{O}}{2 f_{S} I_{O}} \\
& =\frac{(1-D) \frac{D V_{P}}{1-D}}{2 f_{S} I_{O}} \\
& =\frac{D V_{P}}{2 f_{S} I_{O}}
\end{aligned}
$$

The PV voltage is relatively constant over the full range of solar intensity [15]. thus the minimum inductances are a function of duty cycle $D$ and the output current of the PV panel $I_{P}$ or a function of duty cycle $D$ and the inductor current $I_{o}$ that feeds the microgrid under a constant switching frequency $\left(f_{s}=20 \mathrm{kHz}\right)$. The characteristics of the minimum inductances under different duty cycles are shown in Figures 3 and 4.

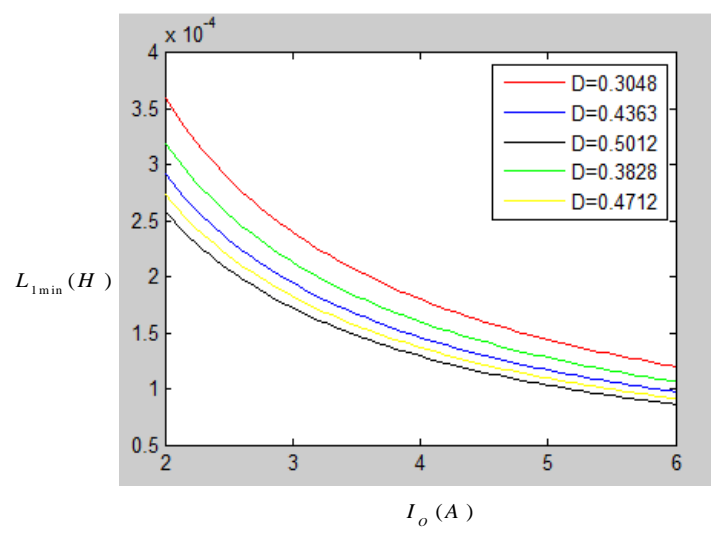

Fig. 3. Characteristic of first minimum inductance under different load conditions of the microgrid.

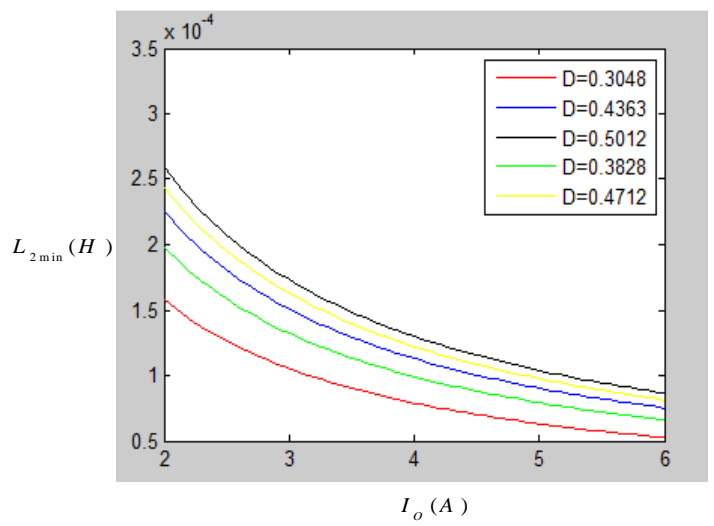

Fig. 4. Characteristic of second minimum inductance under different load conditions of the microgrid.

Evidently, the minimum inductance to achieve CCM falls off as the solar intensity increases. Conversely, the higher value of inductance required at light loads may be achieved without increasing the volume of the inductor. Variable inductance may be achieved using a sloped air gap, whereby the inductor core progressively saturates with increasing current [16]. Alternatively, a powdered iron core may be used so that it is progressively saturated with increasing current to yield the $L-i$ characteristics of Fig .5. The use of a reconfigurable inductor in a boost circuit for PV microgrid applications is described in [17].

\section{CHARACTERISTIC OF VARIABLE INDUCTOR}

The role of the variable inductor in the stable operation of the Cuk converter is explained by reference to Fig. 5 . Continuous conduction can only be achieved with inductance values above the dashed line in Fig 5 (the shaded area is off limits). In Fig. 5(a), the lower limit of load current (corresponding to low solar insolation) is given by $I_{o a, 1}$ as long as the inductance is greater than $L_{a, 1}$. Evidently, at higher currents (and higher insolation levels), say $I_{o b, 1}$, a smaller inductor $L_{b, 1}$ would suffice, with the added advantage of a reduced volume occupied by 
the inductor. Conversely, setting the inductance at $L_{b, 1}$ would limit the lower load range to values of current (and solar insolation) greater than $I_{o b, 1}$. Similarly, In Fig. 5(b), the lower limit of load current (corresponding to low solar insolation) is given by $I_{o a, 2}$ as long as the inductance is greater than $L_{a, 2}$. Evidently, at higher currents (and higher insolation levels), say $I_{o b, 2}$, a smaller inductor $L_{b, 2}$ would suffice, with the added advantage of a reduced volume occupied by the inductor. Conversely, setting the inductance at $L_{b, 2}$ would limit the lower load range to values of current (and solar insolation) greater than $I_{o b, 2}$. The variable inductor with the $L-i$ characteristic shown in Fig .5 has the advantages of increasing the load range [17]. The increased inductance at low insolation levels maintains continuous conduction, and this in turn, means that the control strategy of the MPPT controller extends to lower power levels; this facilitates the extension of the MPPT algorithm to partial shading.

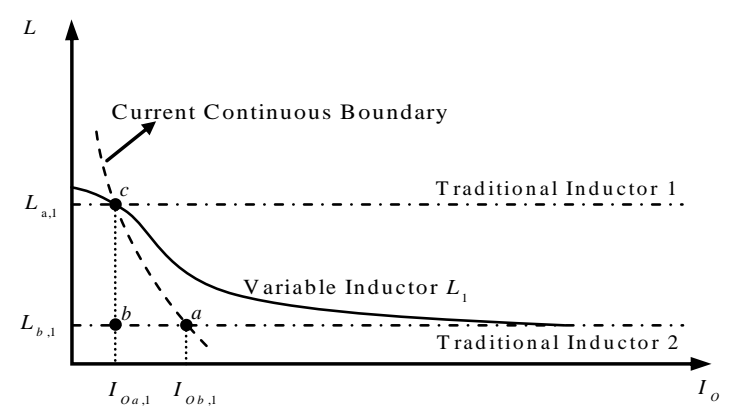

(a)

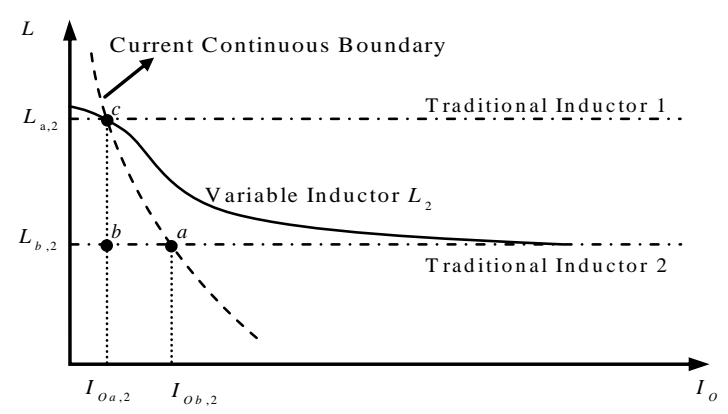

(b)

Fig. 5. Comparison of CCM conditions in an MPPT Cuk converter with a variable inductance, (a) first variable inductance, (b) second variable inductance.

According to the definition, relationship between current and flux in Linear time-invariant inductors as follows: $\phi(t)=L i(t)$

Where $L$ is constant value and is independent of time and current.

The voltage across the inductor and the equation of this type as follows:

$v(t)=L \frac{d i}{d t}$

In this paper, variable inductance is proposed. So, relationship between current and flux in this type is:

$\phi=L(i) i$

The voltage across the inductor and the equation of this type as follows:

$v(t)=\frac{d \phi}{d t}$

$=L \frac{d i}{d t}+i \frac{d L}{d t}$

$=\left(L+i \frac{d L}{d i}\right) \frac{d i}{d t}$ 


$$
=L_{e f f} \frac{d i}{d t}
$$

$L_{e f f}$ in (15) is readily found from the $L-i$ characteristic of the inductor.

\section{SIMULATION RESULTS}

Energy transfer for the Cuk converter depends on the capacitor $C_{1}$. Generally good design makes a save on the cost of every Element. So, designed capacitor value is very important. The ripple in $C_{1}$ can be estimated by computing the change in $v_{C 1}$ in the interval when the switch is open and the currents $i_{L 1}$ and $i_{C 1}$ are the same. Assuming the current in $L_{1}$ to be constant at a level $i_{L 1}$, we can write:

$$
\Delta v_{C 1} \approx \frac{1}{C_{1}} \int_{D T}^{T} I_{L 1} d t=\frac{I_{L 1}}{C_{1}}(1-D) T
$$

The relationship between the output and input currents and voltages in Cuk converter is [14]:

$\frac{I_{L 1}}{I_{L 2}}=\frac{D}{1-D}$

$\frac{V_{P}}{V_{o}}=\frac{1-D}{D}$

By combining (16)-(18) we can write:

$$
\Delta v_{C 1} \approx \frac{V_{P}}{R_{L} C_{1} f_{S}}\left(\frac{D^{2}}{1-D}\right)=\frac{V_{o} D}{R_{L} C_{1} f_{S}}
$$

Table 1. Parameters under different load conditions

\begin{tabular}{|c|c|c|c|c|c|c|c|c|c|c|}
\hline $\begin{array}{c}\text { Insolation } \\
\left(W / m^{2}\right)\end{array}$ & $V_{P}(V)$ & $I_{P}(A)$ & $I_{L 1}(A)$ & $I_{L 2}(A)$ & $P_{O}(W)$ & $D$ & $L_{1 \mathrm{~min}}(\mu H)$ & $L_{2 \min }(\mu H)$ & $r(\Omega)$ & $\begin{array}{c}B \text { uck } \\
\text { or } \\
\text { Boost }\end{array}$ \\
\hline $\mathbf{2 0 0}$ & 41.6 & 1 & 1 & 2.2808 & 41.6 & 0.3048 & 317.1 & 139.04 & 41.6 & Buck \\
\hline $\mathbf{4 0 0}$ & 41.6 & 2 & 2 & 3.2247 & 83.2 & 0.3828 & 199.03 & 123.44 & 20.8 & Buck \\
\hline $\mathbf{6 0 0}$ & 41.4 & 3.1 & 3.1 & 4.0052 & 128 & 0.4363 & 145.6 & 112.74 & 13.354 & Buck \\
\hline $\mathbf{8 0 0}$ & 41.3 & 4.1 & 4.1 & 4.6012 & 169 & 0.4712 & 118.6 & 105.76 & 10.0732 & Buck \\
\hline $\mathbf{1 0 0 0}$ & 41.2 & 5.2 & 5.2 & 5.1751 & 214.24 & 0.5012 & 99.2 & 99.76 & 7.9231 & Boost \\
\hline
\end{tabular}

Note that the components on the output $\left(L_{2}, C_{2}\right.$, and $R$ ) are in the same configuration as the buck converter and that the inductor current has the same form as for the buck converter. Therefore, the ripple or variation in output voltage, is the same as for the buck converter:

$$
\frac{\Delta V_{o}}{V_{o}}=\frac{(1-D)}{8 L_{2} C_{2} f_{S}^{2}}
$$

Now to design the $C_{1}$ and $C_{2}$, the relation (19) is used:

$$
C_{1}=\frac{V_{O} D}{R_{L} f_{S}\left(\Delta v_{C 1}\right)}
$$

If the $\Delta v_{C 1}=1.5 v$ is acceptable, by refer to Table 1 capacitor value will be $86.452 \mu \mathrm{F}$.

To design $C_{2}$, the relation (20) is used:

$$
C_{2}=\frac{(1-D)}{8 L_{2} f_{s}{ }^{2}\left(\frac{\Delta V_{o}}{V_{o}}\right)}
$$

If the amount of output voltage ripple is not more than $1 \%$, capacitor value will be $156.2 \mu \mathrm{F}$.

Figures 6 and 7 show the simulation results. PSCAD/EMTDC software has been used for simulation and the effect of inductors resistors are ignored in the simulation. The solar insolation changes from 200 to 1000 $W / m^{2}$. Table 1 describes the parameters of the circuit under different solar insolation. Switching frequency is assumed $20 \mathrm{kHz}$ in conduction current mode. 


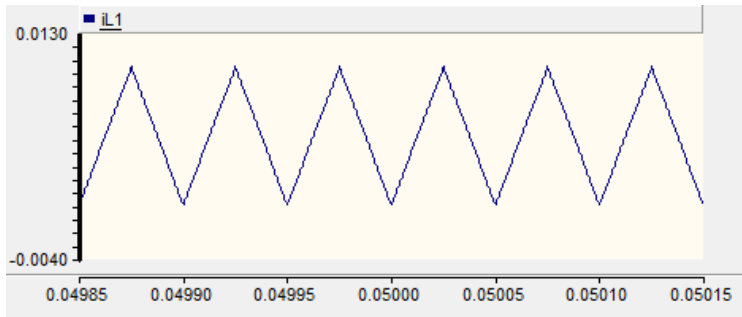

(a)

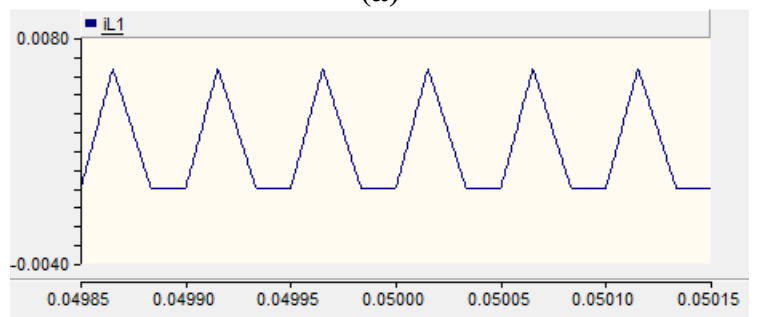

(b)

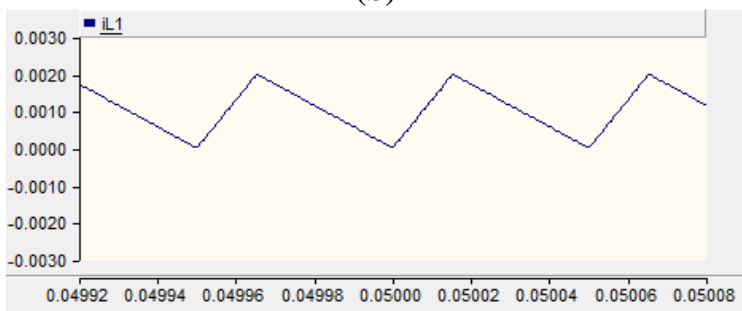

(c)

Fig. 6. Simulation results of first inductor current under different conditions, (a) $L_{1}=99.2 \mu H, L_{2}=99.76 \mu H \quad$ at $1000 \mathrm{~W} / \mathrm{m}^{2}$, (b) $L_{1}=99.2 \mu \mathrm{H}, L_{2}=99.76 \mu \mathrm{H}$ at $200 \mathrm{~W} / \mathrm{m}^{2}$, (c) Variable inductor at $200 \mathrm{~W} / \mathrm{m}^{2}$.

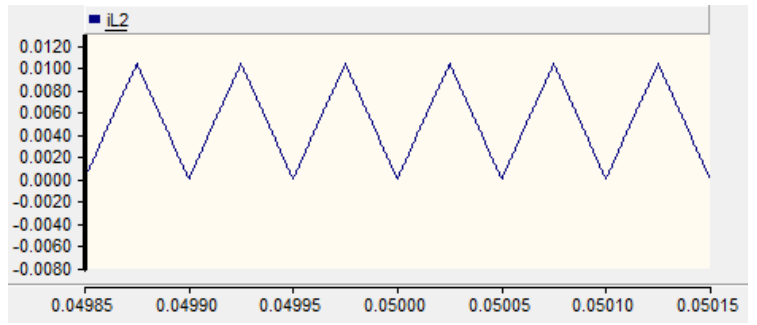

(a)

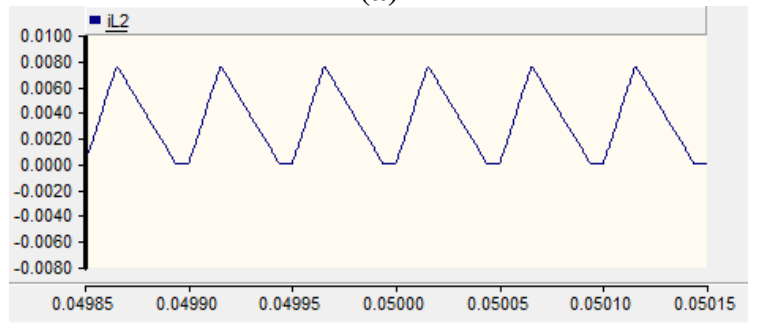

(b)

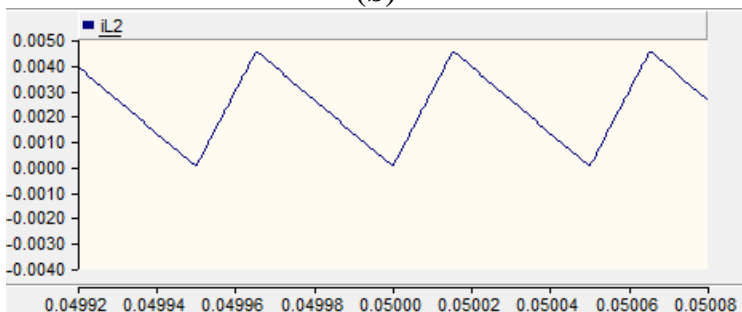

(c)

Fig. 7. Simulation results of second inductor current under different conditions, (a) $L_{1}=99.2 \mu H, L_{2}=99.76 \mu H$ at $1000 \mathrm{~W} / \mathrm{m}^{2}$, (b) $L_{1}=99.2 \mu \mathrm{H}, L_{2}=99.76 \mu \mathrm{H}$ at $200 \mathrm{~W} / \mathrm{m}^{2}$, (c) Variable inductor at $200 \mathrm{~W} / \mathrm{m}^{2}$. 
Figure 6(a) shows the first inductor current for $L_{1}=99.2 \mu \mathrm{H}$ and $L_{2}=99.76 \mu \mathrm{H}$ at $1000 \mathrm{~W} / \mathrm{m}^{2}$ and the current is continuous. Figure 6(b) shows the inductor current for $L_{1}=99.2 \mu \mathrm{H}$ and $L_{2}=99.76 \mu \mathrm{H}$ at 200 $W / m^{2}$, and as expected, the converter is operating in discontinuous mode. Repeating the simulation for a variable inductor at $200 \mathrm{~W} / \mathrm{m}^{2}$ in Figure 6(c) shows that continuous conduction has been restored. Similarly, Figure 7(a) shows the second inductor current for $L_{1}=99.2 \mu \mathrm{H}$ and $L_{2}=99.76 \mu \mathrm{H}$ at $1000 \mathrm{~W} / \mathrm{m}^{2}$ and the current is continuous. Figure 7(b) shows the inductor current for $L_{1}=99.2 \mu \mathrm{H}$ and $L_{2}=99.76 \mu \mathrm{H}$ at $200 \mathrm{~W} / \mathrm{m}^{2}$, and as expected, the converter is operating in discontinuous mode. Repeating the simulation for a variable inductor at $200 \mathrm{~W} / \mathrm{m}^{2}$ in Fig. 7(c) shows that continuous conduction has been restored. In Figures 6 and 7 , inductors current is perunit and base current is $1 \mathrm{kA}$.

Figure 8(a) shows the internal resistance of the PV to operate on the maximum power point. the internal resistance of the PV should be equal to the regulated resistance.

Figures 8(b) and 8(c) shows the minimum inductances under different solar insolation.

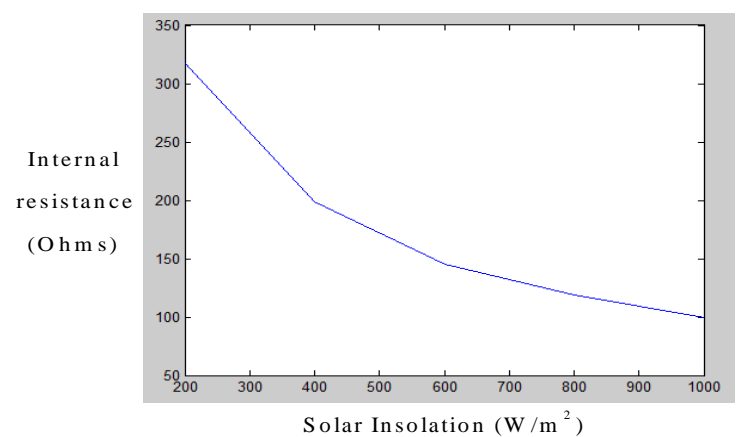

(a)

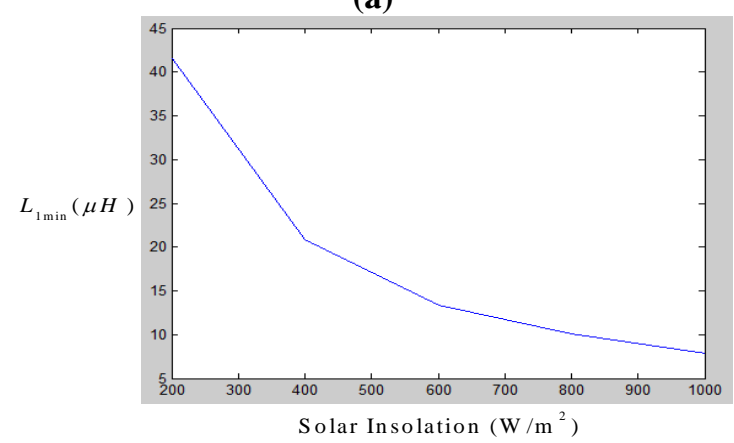

(b)

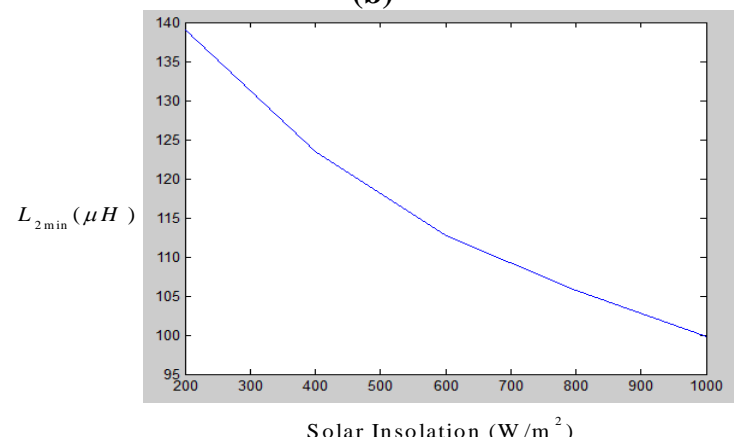

(c)

Fig. 8. (a) Internal resistance, (b) first variable inductance, (c) second variable inductance. 


\section{CONCLUSION}

This paper presents a new topology of an MPPT controller for solar microgrid applications that incorporates variable inductances. The used $\mathrm{dc}$ to $\mathrm{dc}$ converter is Cuk converter with variable inductors. The increased inductances at low insolation levels maintain continuous conduction and the control strategy of the MPPT controller extends to lower power levels; this facilitates the extension of the MPPT algorithm to partial shading. Good design of capacitors of Cuk converter has been presented, too.

\section{REFERENCES}

[1]. X. Yaosuo, C. Liuchen, K. B. Sren, J. Bordonau, and T. Shimizu, "Topologies of single-phase inverters for small distributed power generators: AnOverview,” IEEE Trans. Power Electron., vol. 19, no. 5, pp. 1305-1314, Sep. 2004

[2]. $\quad$ B. M. T. Ho and H. S.-H. Chung, "An integrated inverter with maximum power tracking for grid-connected PV systems," IEEE Trans. Power Electron., vol. 20, no. 4, pp. 953-962, Jul. 2005.

[3]. M. Liserre, R. Teodorescu, and F. Blaabjerg, "Stability of photovoltaic and wind turbine grid-connected inverters for a large set of grid impedance values," IEEE Trans. Power Electron., vol. 21, no. 1, pp. 263-272, Jan. 2006.

[4]. N. Pogaku, M. Prodanovic, and T. C. Green, "Modeling, analysis and testing of autonomous operation of an inverter-based microgrid," IEEE Trans. Power Electron., vol. 22, no. 2, pp. 613-625, Mar. 2007.

[5]. S. Jain and V. Agarwal, "A single-stage grid connected inverter topology for solar PV systems with maximum power point tracking," IEEE Trans. Power Electron., vol. 22, no. 5, pp. 1928-1940, Sep. 2007.

[6]. T. Noguchi, S. Togashi and R. Nakamoto, "Short-current pulse-based maximum-power-point tracking method for multiple photovoltaic-and-converter module system," IEEE Trans. Ind Electron., vol. 49, no. 1, pp. 217-223, Feb 2002.

[7]. L. Quan and P. Wolfs, "A review of the single phase photovoltaic module integrated converter topologies with three different DC link configurations," IEEE Trans. Power Electron., vol. 23, no. 3, pp. 1320-1333, May 2008.

[8]. B. H. Chowdhury and A. W. Sawab, "Evaluation of current controllers for distributed power generation systems," IEEE Trans. Power Electron., vol. 24, no. 3, pp. 654-664, Mar. 2009.

[9]. M. G. Villalva, J. R. Gazoli, and E. R. Filho, "Comprehensive approach to modeling and simulation of photovoltaic arrays," IEEE Trans. Power Electron., vol. 24, no. 5, pp. 1198-1208, May 2009.

[10]. Q. Li and P.Wolfs, "A review of the single phase photovoltaic module integrated converter topologies with three different DC link configurations," IEEE Trans. Power Electron., vol. 23, no. 3, pp. 1320-1333, May 2008.

[11]. H. Oldenkamp and I. de Jong, "The return of the AC-module inverter," in Proc. Eur. Photovoltaic Solar Energy Conf. Exhib., Sep. 21-25, 2009, pp. 1-4.

[12]. S. Jiang, D. Cao, Y. Li, and F. Z. Peng, "Grid-connected boost-half-bridge photovoltaic microinverter system using repetitive current control and maximum power point tracking," IEEE Trans. Power Electron., vol. 27, no. 11, pp. 4711-4722, Nov. 2012.

[13]. H. Hu, S. Harb, X. Fang, D. Zhang, Q. Zhang, Z. J. Shen, and I. Batarseh, "A three-port flyback for PV microinverter applications with power pulsation decoupling capability," IEEE Trans. Power Electron., vol. 27, no. 9, pp. 3953-3964, Sep. 2012.

[14]. Mohan Ned, Undeland T.M. and Robbins W.P., "Power Electronics: Converters, Applications and Design.” John Wiley and Sons, Second Edition, 2001.

[15]. SANYO HIP 210-BO-1 Datasheet, 2010, Sanyo Electric Co., Ltd. Available: http://www.solargy.com.sg/pdtsvc.php?subcat=HSPVP\&pid=HIP-210

[16]. W. H. W“olfle and W. G. Hurley, "Quasi-active power factor correction with a variable inductive filter: theory, design, and practice," IEEE Trans. Power Electron., vol. 18, no. 1, pp. 248-255, Jan. 2003.

[17]. N. D. Benavides and P. L. Chapman, "Boost converter with a reconfigurable inductor," in Proc. IEEE Power Electron. Specialists Conf., Orlando, FL, 2007, pp. 1695-1700. 